\title{
Treating Negative Symptoms in Schizophrenia: an Update
}

Gary Remington, M.D., Ph.D., F.R.C.P.C. 1,2,3, *

George Foussias, M.D.,Ph.D., F.R.C.P.C. ${ }^{1,2,3}$

Gagan Fervaha, Ph.D. (Candidate) ${ }^{2,3}$

Ofer Agid, M.D. ${ }^{1,2,3}$

Hiroyoshi Takeuchi, M.D., Ph.D. ${ }^{1,4,3}$

Jimmy Lee, M.B.B.S., M.Med. (Psychiatry), M.C.I. ${ }^{5,3}$

Margaret Hahn, MD. Ph.D., F.R.C.P.C. ${ }^{1,2,3}$

\author{
Address \\ *,1Department of Psychiatry, University of Toronto, Toronto, 0N, Canada \\ Email: gary.remington@camh.ca \\ ${ }^{2}$ Institute of Medical Science, University of Toronto, Toronto, ON, Canada \\ ${ }^{3}$ Centre for Addiction and Mental Health (CAMH), 250 College St., Toronto, ON, \\ M5T 1R8, Canada \\ ${ }^{4}$ Department of Neuropsychiatry, Keio University School of Medicine, Tokyo, \\ Japan \\ ${ }^{5}$ Department of General Psychiatry 1, Institute of Mental Health, 10 Buangkok \\ View, 539747, Singapore, Singapore
}

Published online: 8 April 2016

(C) The Author(s) 2016. This article is published with open access at Springerlink.com

This article is part of the Topical Collection on Schizophrenia and Other

Psychotic Disorders

Keywords Schizophrenia · Negative symptoms · Treatment · Pharmacotherapy · Brain stimulation

\section{Opinion Statement}

Interest in the negative symptoms of schizophrenia has increased rapidly over the last several decades, paralleling a growing interest in functional, in addition to clinical, recovery, and evidence underscoring the importance negative symptoms play in the former. Efforts continue to better define and measure negative symptoms, distinguish their impact from that of other symptom domains, and establish effective treatments as well as trials to assess these. Multiple interventions have been the subject of investigation, to date, including numerous pharmacological strategies, brain stimulation, and nonsomatic approaches. Level and quality of evidence vary considerably, but to this point, no specific treatment can be recommended. This is particularly problematic for individuals burdened with negative symptoms in the face of mild or absent positive symptoms. Presently, clinicians will sometimes turn to interventions that are seen as more "benign" and in line with routine clinical practice. Strategies include use of atypical antipsychotics, ensuring the lowest possible antipsychotic dose that maintains control of positive 
symptoms (this can involve a shift from antipsychotic polypharmacy to monotherapy), possibly an antidepressant trial (given diagnostic uncertainty and the frequent use of these drugs in schizophrenia), and non-somatic interventions (e.g., cognitive behavioral therapy, CBT). The array and diversity of strategies currently under investigation highlight the lack of evidence-based treatments and our limited understanding regarding negative symptoms underlying etiology and pathophysiology. Their onset, which can precede the first psychotic break, also means that treatments are delayed. From this perspective, identification of biomarkers and/or endophenotypes permitting earlier diagnosis and intervention may serve to improve treatment efficacy as well as outcomes.

\section{Introduction}

Paralleling the advent of the second generation or "atypical" antipsychotics (SGAs) in the 1990s has been several important shifts in how schizophrenia is conceptualized. First, it has transitioned from an illness defined by psychosis to one reflecting multiple symptom domains. Interest in negative symptoms had been generated by work through the 1980s, but the picture broadened to include, in particular, cognitive symptoms. Second, discussions regarding outcome began to firmly embrace the notion of functional versus clinical recovery, the latter historically enmeshed in resolution of positive symptoms (e.g., hallucinations, delusions). The third shift related to antipsychotics themselves. Early evidence was seen as indicating that the newer drugs, with their different pharmacology, could effectively treat these other domains, giving rise to the notion that they were much more than antipsychosis agents.
With over two decades of clinical experience involving these newer drugs now behind us, there have been further changes in thinking. Enthusiasm regarding the clinical benefits of SGAs for symptoms beyond psychosis has been tempered considerably based on accumulated evidence [1]. At the same time, the relevance of both negative and cognitive symptoms in terms of functional recovery [2] has become central to rapidly expanding efforts focused on: (a) better understanding these domains and (b) establishing effective treatments. Indeed, it is not uncommon to see new treatments evaluated on both domains. However, the focus here will be negative symptoms, an updated appraisal of somatic treatments over the last several years, and an overview of challenges and opportunities as we move forward. The gold standard will be meta-analyses where negative symptoms have been the primary outcome, followed by more global meta-analyses and recent randomized controlled trials (RCTs).

\section{Negative symptoms}

Central to the work arising out of the 1980s was the distinction between primary (i.e., deficit) and secondary negative symptoms [3], although clinically they can be indistinguishable. More recently, the National Institute of Mental Health (NIMH) Measurement and Treatment Research to Improve Cognition in Schizophrenia (MATRICS) turned its attention to negative symptoms. From a treatment perspective, it is noteworthy that the MATRICS consensus statement makes reference to persistent negative symptoms and indicates the distinction between primary and secondary negative symptoms is not essential [4]. In addition, the following features are identified: affective flattening, alogia, avolition, asociality, and anhedonia [4, 5]. Factor analyses have isolated two separate but related subdomains, diminished expression (e.g., affective flattening), and amotivation (e.g., avolition/apathy) [6]. 
While debate continues regarding the interrelationship and contribution of negative versus cognitive (both social cognition and neurocognition) symptoms to functional impairment, it is clear that their impact is substantial. Resolution of positive symptoms, even in the early stages of schizophrenia, does not necessarily translate to functional recovery; figures suggest that full functional/social recovery occurs in less than $15 \%$ of individuals with schizophrenia, with negative symptoms playing a significant role [7]. To this last point, work focusing on the prodrome of schizophrenia indicates that deficit symptoms and cognitive impairment are evident by the time of the first psychotic break [8,9], while enduring primary negative symptoms have been identified in approximately $25-30 \%$ of individuals with chronic schizophrenia [10].

\section{Treatment}

The very nature of negative symptoms has implications regarding pathophysiology and treatment. Whereas positive symptoms are framed in the context of excess activity (e.g., hyperdopaminergia), negative symptoms, at least historically, have been conceptualized as reflecting a loss of functioning [11]. This position was central to the early work distinguishing positive and negative symptoms, where negative symptoms were associated with structural CNS changes. As a result, it was postulated that these features would not be amenable to pharmacotherapy in the same fashion as positive symptoms [12]. This said, how negative symptoms are conceptualized has shifted and numerous lines of investigation have been undertaken based on the notion that somatic as well as non-somatic interventions may well effect improvement in the so-called primary negative symptoms.

The level of interest and enthusiasm are reflected in the number of reviews on this topic in just the last 2 years, with a cluster of these, including a recent meta-analysis, specifically addressing treatment [13, $14,15 \bullet \bullet, 16-18]$. This article follows the format of at least some of these recent reviews, summarizing and updating the research according to psychiatric medication class (antipsychotics, antidepressants, CNS stimulants, anticonvulsants) or highlighted site/mechanism of action (glutamate, acetylcholine, serotonin, sex hormones, inflammation-immunology). Brain stimulation is also reviewed, although non-somatic treatments are not; the reader is referred to several of the aforementioned reviews for such information [16, 18]. Finally, it is important to highlight the fact that these different interventions are, as a rule, carried out in the face of concomitant antipsychotic treatment, the exception being trials involving newer antipsychotics.

The notion that pharmacological treatment could favorably influence negative symptoms gained its foothold in the seminal work in the 1980s positioning clozapine as unique amongst antipsychotics in treatment-resistant schizophrenia (TRS). The so-called atypical antipsychotics that followed thereafter have been seen as sharing this same feature, including those more recently being investigated that highlight newer mechanisms of action [19]. Further to this last 
point, different theories have been posited to account for atypicality, including serotonin 5- $\mathrm{HT}_{2}$ /dopamine $\mathrm{D}_{2}$ antagonism and fast dissociation from the $\mathrm{D}_{2}$ receptor; more recently, a third generation of antipsychotics has been designated, with aripiprazole the prototype, characterized by partial dopamine agonist properties [20]. While studies continue to compare newer antipsychotics, findings do not support a significant difference between atypical antipsychotics in the treatment of negative symptoms [21-23]. Evidence, to date,

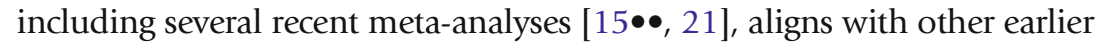
studies indicating: (a) the newer antipsychotics are not superior to their conventional counterparts in the treatment of negative symptoms and (b) the effect in either case is modest.

Notwithstanding the challenges in distinguishing negative and depressive symptoms clinically, an extensive body of literature has accumulated on the efficacy of antidepressants in the treatment of negative symptoms. This has generated a number of meta-analyses addressing this topic, some of which look beyond antidepressants as a class to specific agents and/or groups categorized by mechanism of action. Two earlier meta-analyses provided equivocal evidence [24] and a lack of support [25], respectively, while the most recent report has supported some evidence of benefits that differs between agents [26]. A commentary on the collective work concluded that the evidence is not strong enough to support their use [27], although trials continue. For example, a recent 12-week placebo-controlled study evaluating buproprion, a dopamine and norepinephrine reuptake inhibitor as well as nicotine receptor antagonist, failed to identify clinical benefits [28]. In contrast, a 12-week RCT comparing reboxetine, a norepinephrine inhibitor (NRI), versus placebo reported a robust effect size in the reboxetine-treated group, although, notably, all subjects in this study were chronic and being treated with haloperidol as the antipsychotic [29]. A recently published meta-analysis looking only at mirtazapine, a noradrenergic and specific serotonergic antidepressant, concluded it demonstrates benefits in the treatment of negative symptoms, but trials included those where negative symptoms were not the primary outcome [30].

Historically, such medications have been seen as contraindicated in individuals with psychosis because of risk of positive symptoms being induced or aggravated. Indeed, for a period of time, such drugs were employed as a challenge to establish risk of relapse [31]. The presence of concomitant antipsychotic treatment seems critical to this argument; for example, clinical data involving childhood schizophrenia and comorbid attention deficit disorder, where individuals received both antipsychotics and psychostimulants, indicated that such a combination was not associated with increased risk of psychosis [32]. The growing focus regarding negative symptoms and their treatment has renewed interest in this class of medications, and a recent review of the topic suggested evidence of benefits, adding that risk is reduced in clinically stable individuals with minimal positive symptoms and concomitant antipsychotic therapy [33]. While earlier trials employed drugs used routinely in 
attention deficit hyperactivity disorder (ADHD) (e.g., methylphenidate, $d$-amphetamine), there has been a shift more recently to trials with drugs used in the treatment of excessive sedation (modafinil, armodafinil). Of note, these drugs constituted a substantial contribution to the aforementioned review [33]; however, a recent meta-analysis reported differences with modafinil or armodafinil in the treatment of negative symptoms, but the effect size was small [34]. In addition, another RCT since noted no benefits with modafinil [35].

Recently, lisdexamfetamine (LDX), a pro-drug of amphetamine licensed for use in ADHD, has been investigated for its possible treatment of negative symptoms in schizophrenia. Favorable results were published based on an open-label, randomized withdrawal phase trial demonstrating improvement in negative symptoms with LDX and no indication of positive or negative symptom worsening with its abrupt discontinuation [36]. However, trials have since been terminated.

\section{Anticonvulsants}

Reference has been made to these drugs in other reviews of negative symptoms $[13,18]$, and, like ECT, these drugs have a long history of augmentation use in schizophrenia as well as specific subpopulations (e.g., clozapine resistance, aggression) [37, 38]. In this context, improvement in negative symptoms as one of a number of outcome measures has been reported, but no controlled studies have specifically examined anticonvulsants for their utility in negative symptoms per se.

\section{Glutamate}

This is one of several areas that has garnered considerable attention in recent years, not only in terms of negative symptoms but positive and cognitive symptoms as well [39•]. In terms of negative symptoms, numerous compounds, involving both ionotropic and metabotropic receptors, have been evaluated over the last two decades. Two meta-analyses, not specific to negative symptoms, suggested a favorable, albeit small, signal supporting the efficacy of drugs enhancing NMDA receptor function (e.g., $d$-serine, sarcosine, $\mathrm{N}$-acetyl-cysteine, D-cycloserine), although the effect was different between agents [40, 41].

More recently, this line of thinking has spawned interest in other compounds that are presently being investigated, at least in part, for their benefits in negative symptoms. While trials continue, results, to date, have been mixed. Notably, a paper published in the last year offered ongoing support for $d$-serine [42], whereas several investigational compounds have been discontinued during early phase development, including agents that act through different mechanisms including glycine transporter 1 (GlyT1) inhibition (e.g., bitopertin) [43] and mGluR2/3positive allosteric modulation (e.g., LY2140023) [44]. Further, there are agents designated as NMDA receptor antagonists that have also been the subject of investigation [45]. Once again, this speaks to the complexity of the glutamatergic system and differences between agents working through different mechanisms of action. Results with these strategies have as well been equivocal. Disappointing results with bitopertin and 
LY2140023 have led to their discontinuation for this indication [14, 46]. In the case of NMDA receptor antagonists, a meta-analysis examining amantadine and memantine did not support the utility of these medications in the treatment of negative symptoms, although the focus was not on negative symptoms specifically [45]. This said, an RCT published subsequently and looking at negative symptoms as the primary outcome reported that memantine led to significant improvement at 8 weeks, with a large effect size (Cohen's $d=1.5$ [95\%CI $0.8-2.22$ ]) [47].

Evidence continues to grow supporting a role for glutamate in processes critical to schizophrenia $[48,49]$, which may account for why, in the face of equivocal clinical evidence, efforts continue in developing new compounds. Suggestions to move the field ahead include the evaluation of other receptors, intracellular pathways, illness subtypes as well as stage of illness, and biomarkers/ endophenotypes [39•, 50-54]. Again, though, this work is not confined only to efficacy regarding negative symptoms or, in fact, schizophrenia.

As in the case of glutamatergic agents, the interest in this area is not specific to negative symptoms; indeed, much of this work has focused on cognitive symptoms as the primary endpoint. An earlier metaanalysis evaluating cholinesterase inhibitors in schizophrenia (rivastigmine, donepezil, galantamine) noted improvement in selected measures of cognition, but not negative symptoms [55]. A subsequent meta-analysis also had as its primary focus cognitive symptoms, and as an aside evaluated both glutamatergic and serotonergic receptors. It did note an effect on negative symptoms with two agents indicated in the treatment of Alzheimer's disease, donepezil, and galantamine [56]; both share in common action as cholinesterase inhibitors while the latter is as well an allosteric modulator of nicotine acetylcholine receptors. A Cochrane review around the same time, and specific to cholinesterase inhibitors in schizophrenia, also suggested a signal for improvement in negative symptoms [57]; once more, though, negative symptoms were not the primary outcome. Further complicating interpretation of results is the need to disentangle the effect of changes in other domains on negative symptom scores [56], in addition to other pharmacological effects; for example, galantamine has been reported to enhance dopamine neurotransmission through its allosteric modulation of nicotinic acetylcholine receptors [58]. To date, no RCTs have been reported involving a cholinesterase inhibitor where negative symptoms were the primary outcome.

Efforts have also included a number of newer $\alpha 7$ nicotinic acetylcholine receptor ( $\alpha 7 \mathrm{nAChR})$ agonists/partial agonists as well as positive allosteric modulators [59-62]. To this point, though, it is difficult to evaluate the clinical benefits of this line of investigation. A recent double-blind trial involving galantamine/CDP-choline did not improve negative symptoms [63], nor did a recent phase 2 trial with the $\alpha 7$ nAChR agonist, TC-5619 [64]. Added to this is the early discontinuation 
of several other such agents [13]. In addition, there is again the issue of other mechanisms of action that may contribute to any effect seen; for example, preclinical evidence has shown that EVP-614, also a $\alpha 7 \mathrm{nAChR}$ agonist, increases cortical $\mathrm{ACh}$ and glutamate release, and this is true for dopamine, too [65]. As an aside, increased dopaminergic and noradrenergic activity has also been reported in association with CPD-choline administration [66].

\section{Serotonin}

The notion that serotonin antagonism may prove useful in the treatment of negative symptoms gained momentum with the early claims that atypical antipsychotics, clozapine being the prototype, were superior to conventional antipsychotics in the treatment of negative symptoms [67]. It was postulated that their concomitant $5-\mathrm{HT}_{2}$ antagonism played a role in this which, in turn, led to the development of selective $5-\mathrm{HT}_{2}$ antagonists that were then investigated further in the treatment of negative (as well as positive) symptoms (e.g., ritanserin, M100907). While several RCTs involving ritanserin offered support for this line of investigation $[68,69]$, the more recent focus has turned to selective $5-\mathrm{HT}_{3}$ antagonists (e.g., ondansetron, tropisetron, granisetron). Several trials specifically focused on negative symptoms have supported their efficacy [70, 71], as does a recent meta-analysis although it evaluated their effects on schizophrenia in general [72].

\section{Sex hormones}

Gender differences have been well established in schizophrenia, with differences reported for age of onset, symptoms, course, and prognosis [73]. Once more, the work arising from this line of investigation is not specific to negative symptoms per se, but there is evidence specific to this topic, including a limited number of RCTs. As a starting point, various studies have identified relationships between neurosteroids/sex hormones and negative symptom severity [74-78]. In terms of RCTs, dehydroepiandrosterone (DHEA), an adrenal hormone involved in the production of androgens and estrogens, has been reported to improve negative symptoms [79], as have studies involving pregnenolone [80, 81]. Most recently, two further investigations specifically examining negative symptoms as part of their primary outcome have been added. In the first, a combination of pregnenolone and $l$-theanine over 8 weeks decreased both negative and anxiety symptoms, the co-primary outcome measures [82], while in the second the addition of raloxifene, an estrogen receptor modulator, decreased negative symptoms over 6 months in post-menopausal females with schizophrenia and prominent negative symptoms [83].

Currently, considerable attention is being given to oxytocin, and there are several recent reviews specific to schizophrenia [84, 85] in addition to a meta-analysis [86]. While much of the focus is on social cognition, its potential in the treatment of negative symptoms is 
highlighted in each. As of yet, there is a lack of studies where it has been specifically evaluated with negative symptoms as the primary focus.

\section{Inflammation-immunology}

Kraepelin originally conceptualized schizophrenia as a neuroprogressive disorder (i.e., dementia praecox or "early dementia") [87]. More recently, though, the focus has shifted to schizophrenia as a disorder of neurodevelopment, and within this framework, there is considerable interest in the role of inflammation and immune response [88]. Following this line of thinking, it is hypothesized that agents impacting the inflammatory response may prove useful in treating symptoms and, perhaps, altering the illness course. Only a limited amount of this work has been specific to negative symptoms, and in this regard, minocycline, a broad-spectrum tetracycline antibiotic with neuroprotective properties mediated through anti-inflammatory, anti-apoptotic, and antioxidant effects [89], has received the greatest attention. A recent meta-analysis supported its value in the treatment of negative symptoms, although this domain was not the primary outcome [90]. RCTs, where this is the case, have been mixed in their findings. There has been one negative trial [91], and another where only one domain, avolition (as measured using the SANS), was significantly impacted [92]. In contrast, two RCTs have reported positive results, one involving chronic schizophrenia [93] and one that looked at early-phase schizophrenia specifically [94]. Two large RCTs, the MINOS Trial and BeneMin, are currently underway, both focusing on early schizophrenia $[95,96]$. Of note, there is interest in looking at schizophrenia across different symptom domains and stages of the illness (e.g., treatment resistance) [97], as well as other conditions where altering immune response may impact outcome (e.g., acute ischemic stroke) [98].

Compounds reviewed in other sections also have the capacity to act in a similar fashion. This would include neurosteroids such as pregnenolone (sex hormones), as well as compounds that modulate NMDA receptor-related inflammatory changes (e.g., $d$-serine, memantine) [42] (glutamate). Other drugs (e.g., ASA, Cox-2 inhibitors) would as well be seen as holding promise in this regard $[18,99]$. Recent RCTs have been reported for dextromethorphan [100], methotrexate [101], interferon $\gamma$ [102], atorvastatin as well as pravastatin [103], and pioglitazone [104] in schizophrenia, although none have focused specifically on negative symptoms. To date, one small RCT evaluating atorvastatin in negative symptoms has reported benefits [105].

This is another line of investigation that currently generates considerable interest reflected in the number of meta-analyses [106-109] and reviews [110] specific to rTMS and negative symptoms in the last few years. Notably, the metaanalyses are consistent in the conclusion that rTMS is beneficial, with the effect size ranging from small and non-significant to as high as 0.80 , the variability reflecting differences in moderators (e.g., study duration, stimulus frequency, outcome measure, illness duration) [106-109]. Further, a just published RCT 


\section{Table 1. Treatment of negative symptoms}

\begin{tabular}{|c|c|c|}
\hline Topic & Literature & Comments \\
\hline $\begin{array}{l}\text { Comprehensive } \\
\text { meta-analysis }\end{array}$ & $\begin{array}{l}\text { A meta-analysis of RCT interventions to } \\
\text { December } 2013 \text { involving } 168 \text { trials } \\
(N=6503 \text { in treatment arm, } N=5815 \text { in } \\
\text { placebo arm). }\end{array}$ & $\begin{array}{l}\text { Treatments evaluated included antipsychotics } \\
\text { (AP, first and second generation), } \\
\text { antidepressants }(A D), \text { pharmacological } \\
\text { combinations (e.g., AP+AP; AP+AD), } \\
\text { glutamatergic agents, brain stimulation, } \\
\text { and psychological interventions. Some } \\
\text { differences were statistically significant } \\
\text { but none reached threshold for clinical } \\
\text { significance }[15 \bullet \bullet]\end{array}$ \\
\hline \multicolumn{3}{|c|}{ Specific somatic interventions } \\
\hline Antipsychotics & $\begin{array}{l}\text { The introduction of "atypical" antipsychotics } \\
\text { came with claims of superior efficacy in the } \\
\text { treatment of negative symptoms. This had } \\
\text { been identified with clozapine in trials } \\
\text { evaluating its efficacy in } \\
\text { treatment-resistant schizophrenia }\end{array}$ & $\begin{array}{l}\text { Modest improvement, not clinically } \\
\text { significant, may be observed with } \\
\text { antipsychotic treatment, possibly related } \\
\text { to efficacy on other symptom domains } \\
\text { and/or dopamine "sparing". Two recent } \\
\text { meta-analyses, one specific to negative } \\
\text { symptoms, do not support superiority of } \\
\text { the newer antipsychotics }[15 \bullet \bullet, 21] \text {. Going } \\
\text { forward, the notion of developing an agent } \\
\text { that can significantly and simultaneously } \\
\text { impact the different symptom domains of } \\
\text { schizophrenia seems unlikely }\end{array}$ \\
\hline Antidepressants & $\begin{array}{l}\text { This work has been built around } \\
\text { augmentation with SSRIs and, more } \\
\text { recently, the newer classes of } \\
\text { antidepressants that have followed }\end{array}$ & $\begin{array}{l}\text { Only one of three earlier meta-analyses } \\
\text { focused on negative symptoms offered } \\
\text { support for such an approach [24-26]. } \\
\text { The fourth and most recent } \\
\text { meta-analysis also did not identify } \\
\text { changes that were clinically significant } \\
{[15 \bullet \bullet \text {. This said, ADs are used }} \\
\text { routinely with APs in schizophrenia } \\
\text { and as they evolve it is likely that new } \\
\text { ADs will be evaluated in negative } \\
\text { symptoms }\end{array}$ \\
\hline CNS stimulants & $\begin{array}{l}\text { This literature has included trials } \\
\text { involving ADHD drugs and, more } \\
\text { recently, drugs indicated in the } \\
\text { treatment of excessive sedation (e.g., } \\
\text { modafanil). Lisdexamfetamine, } \\
\text { indicated for ADHD, was recently } \\
\text { evaluated for a possible indication in } \\
\text { negative symptoms but this line of } \\
\text { investigation has been terminated }\end{array}$ & $\begin{array}{l}\text { Collectively, this line of investigation has } \\
\text { established that such agents can be used } \\
\text { safely in individuals with psychosis. A } \\
\text { review in } 2013 \text { specific to negative } \\
\text { symptoms concluded evidence supports } \\
\text { larger trials be done [33], although a more } \\
\text { recent meta-analysis confined to } \\
\text { modafanil/armodafanil reported only a } \\
\text { small effect size [34] }\end{array}$ \\
\hline Anticonvulsants & $\begin{array}{l}\text { Anticonvulsants are frequently used in } \\
\text { schizophrenia and it is in this context } \\
\text { that a potential effect on negative } \\
\text { symptoms has been reported }\end{array}$ & $\begin{array}{l}\text { This area has not generated a lot of interest. } \\
\text { To date, there are no published RCTs } \\
\text { specifically evaluating this class of } \\
\text { medications in trials focused on negative } \\
\text { symptoms }\end{array}$ \\
\hline
\end{tabular}


Table 1. (Continued)

\section{Topic}

Glutamate

Acetylcholine

Serotonin

Sex Hormones

Inflammation/Immunology

\section{Literature}

This line of investigation has garnered a great deal of research although drawing conclusions is complicated by different mechanisms of action. Much of this work is not confined to negative symptoms per se

This focus has also garnered considerable interest in recent years, but once again the focus is not specific to negative symptoms. The research can be divided into work involving cholinesterase inhibitors (e.g., donepezil) and a newer group of $\alpha 7$ nAChR agonists/partial agonists as well as positive allosteric modulators

Earlier work involving selective $5-\mathrm{HT}_{2}$ antagonists (e.g., ritanserin) has given way to research focused on $5-\mathrm{HT}_{3}$ agents (e.g., ondansetron)

Support for this line of investigation arises from work identifying a relationship between neurosteroids/sex hormones and negative symptom severity, in addition to treatment trials

\section{Comments}

Two earlier meta-analyses, not specific to negative symptoms, suggested these drugs could be effective $[40,41]$, and a recent small RCT $(N=35)$ involving d-serine supported this position [42]. However, trials with agents working through other mechanisms (e.g., bitopertin, LY2140023) have been terminated for this indication. A meta-analysis examining NMDA antagonists (8 studies, $N=406$ ) did not support their use in negative symptoms [45], but a small RCT $(N=40)$ since reported a large effect size [47]. The recently published meta-analysis looking at numerous treatments did not report clinically significant results for

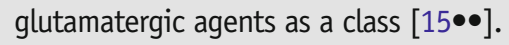
Despite these mixed results, work along these lines is likely to continue

Three meta-analyses examining the cholinesterase inhibitors, but not specific to negative symptoms, have suggested potential benefits [55-57] but no such RCTs have been published as of yet. Taken together, results with the newer $\alpha 7 \mathrm{nAChR}$ agents have not been favorable, and it is presently unclear if efforts specific to negative symptoms will be continued

A recent meta-analysis looking at different domains in schizophrenia has offered support for this approach [72], as have several RCTs specific to negative symptoms $[70,71]$

A small number of trials specific to negative symptoms, and utilizing different agents (DHEA, pregnenolone, raloxifene) have been carried out, with favorable results [80-83]. Oxytocin is receiving considerable attention at present, particularly in terms of measures of social cognition. A recent meta-analysis indicated it may have a role to play in schizophrenia and alluded to some evidence regarding its value in negative symptoms [86]. As of yet, though, specific trials of this sort have not been published

Much of the work to date has involved minocycline, with RCTs specific to negative 
Table 1. (Continued)

\begin{tabular}{|c|c|c|}
\hline Topic & Literature & Comments \\
\hline & $\begin{array}{l}\text { models of schizophrenia and, like other } \\
\text { areas discussed, is not specific to negative } \\
\text { symptoms or, in fact, schizophrenia }\end{array}$ & $\begin{array}{l}\text { symptoms providing mixed results } \\
\text { [91-94]. Compounds reviewed under other } \\
\text { categories here (e.g., } d \text {-serine } \\
\text { [Glutamate); pregnenolone [Sex } \\
\text { Hormones]) may, at least in part, establish } \\
\text { their response through these mechanisms } \\
\text { as well. Larger trials with minocycline are } \\
\text { underway }[95,96], \text { and it can be expected } \\
\text { that other agents will be evaluated in trials } \\
\text { where negative symptoms are the primary } \\
\text { outcome }\end{array}$ \\
\hline Brain Stimulation & $\begin{array}{l}\text { Brain stimulation, including both ECT and } \\
\text { rTMS, has a history in refractory forms of } \\
\text { schizophrenia (e.g., TRS, refractory } \\
\text { hallucinations) although considerable } \\
\text { work with rTMS is now focused on negative } \\
\text { symptoms }\end{array}$ & 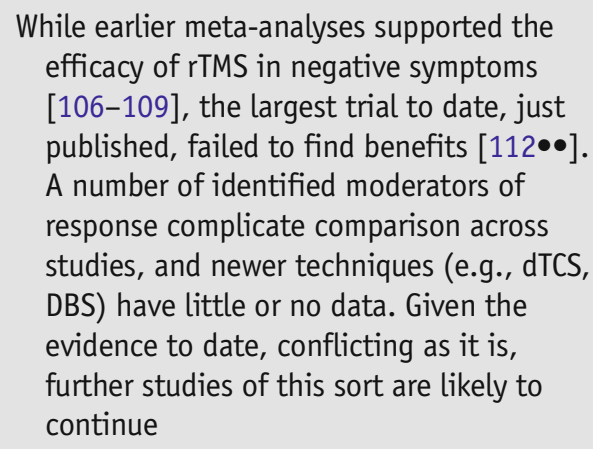 \\
\hline
\end{tabular}

indicated that response with active treatment is sustained over a 24-week follow-up [111]. However, another recently published RCT $(n=175)$ failed to establish a beneficial effect with active versus sham rTMS [112••]. Given the many moderators that can impact outcome, it is difficult to reconcile these findings with the numerous earlier reports and meta-analyses, but the most recent investigation is by far the largest in terms of sample size.

Going forward, there is interest in deep rTMS and its impact on such features as negative symptoms in schizophrenia [113], but it remains for future investigations to address this line of investigation. Transdirect current stimulation (tDCS) is being pursued in the treatment of schizophrenia, and a recent review has concluded that it may prove useful for negative symptoms [114]; to date, however, there is only one small RCT published, although results are favorable regarding negative symptoms [115].

Other forms of brain stimulation remain of interest, but as of yet have been the subject of much less investigation. Electroconvulsive therapy (ECT) has a long history as a treatment in schizophrenia, although at this point is largely confined to augmentation in TRS; in fact, it is amongst the recommended options in the face of partial clozapine response (i.e., ultra-resistant schizophrenia) [116]. While TRS is generally characterized by positive symptoms, a small body of literature has recently reported success in the management of TRS 
with prominent negative symptoms [117-119]. However, these preliminary results have not been corroborated by RCTs.

Repeated vagus nerve stimulation (rVNS) has been identified as useful in other medical and psychiatric conditions (e.g., epilepsy, depression), and a recent randomized, sham controlled and double-blind study evaluated its efficacy in schizophrenia, although efficacy was not established across any outcome measure, including negative symptoms [120]. Deep brain stimulation (DBS) has also found a role in the treatment of different medical and psychiatric conditions, and while there is interest and a rationale for use in negative symptoms [121], no such studies have been published as of yet.

\section{Conclusions}

Table 1 summarizes the literature discussed. As concluded in the recently

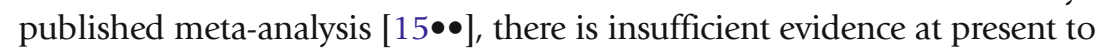
support a specific treatment for negative symptoms. This is despite a tremendous increase in interest in the topic, as well as studies where negative symptoms are the identified primary outcome.

A number of factors may contribute to the lack of success to date. Diagnostically, it is difficult distinguishing primary from secondary negative symptoms, just as it is a challenge differentiating negative symptoms from other psychiatric diagnoses such as depression. Our understanding regarding underlying pathophysiological processes is not well established, resulting in strategies for treatment that are, at best, speculative. This is perhaps best captured by the numerous trials that choose to assess multiple symptom domains rather than focusing specifically on negative symptoms. From a conceptual standpoint, the very definition of negative symptoms represents a work in progress, and it has been demonstrated that outcomes can be influenced by the measures employed [16, 122]. More recently, guidelines have been forwarded regarding study trial design [123•], but, in fact, much of the work to this point falls short of these standards. It is now common to isolate different components under the framework of negative symptoms [6], but this strategy is in its earliest stages and it is unclear how these may differentially respond to treatment. We continue to seek biomarkers and/or endophenotypes that may not only improve diagnosis but, in addition, advance the field in clinical subtyping; already, different trajectories have been reported [124] but this work too is in its earliest stages. It has been established that negative symptoms predate the onset of positive symptoms, and there is speculation that aberrations occurring during neurodevelopment are responsible. This underscores the importance of timing of interventions, and expectations regarding the success of treatments that are implemented later in the illness course. Indeed, it is possible that effective treatments await that time when we can reliably identify those who will go on to develop schizophrenia, which would also permit interventions well in advance of when diagnosis occurs, that is when psychotic features are evident for the first time. Where benefits have been recorded to this point, the reported effect size is often not of a magnitude to be clinically significant $[15 \bullet \bullet]$. Finally, there is evidence that non-biological factors may play a role $[125,126]$, which raises questions as to the limitations of somatic interventions and the need to investigate their benefits in combination with nonbiological strategies. 
Future drug development in the field of schizophrenia clearly identifies negative symptoms as an important unmet need [127]. This is undoubtedly driven, at least in part, by evidence that negative symptoms play a critical role in the functional decline observed in many individuals with schizophrenia, a decline that is not necessarily addressed with adequate control of positive symptoms. What is less clear, however, is what lines of investigation hold promise of success or, in fact, whether effective strategies can be developed until we are able to reliably diagnose schizophrenia and implement treatments earlier in the illness' evolution.

\section{Compliance with Ethical Standards}

\section{Conflict of Interest}

Gagan Fervaha declares that he has no conflict of interest.

Margaret Hahn declares that she has no conflict of interest.

Gary Remington reports personal fees from Novartis, outside the submitted work.

George Foussias reports personal fees from Hoffman-La Roche, personal fees from Lunbeck, outside the submitted work.

Ofer Agid reports grants and personal fees from Janssen-Ortho (Johnson \& Johnson), personal fees from Novartis; grants and personal fees from Sunovion; personal fees from Lundbeck; personal fees from Mylan Pharmaceuticals; and personal fees from Otsuka, outside the submitted work.

Hiroyoshi Takeuchi reports grants from Canadian Institutes of Health Research (CIHR) and personal fees from Dainippon Sumitomo Pharma, outside the submitted work.

Jimmy Lee reports personal fees from Roche during the conduct of the study.

\section{Human and Animal Rights and Informed Consent}

This article does not contain any studies with human or animal subjects performed by any of the authors.

Open Access This article is distributed under the terms of the Creative Commons Attribution 4.0 International License (http://creativecommons.org/licenses/by/4.0/), which permits unrestricted use, distribution, and reproduction in any medium, provided you give appropriate credit to the original author(s) and the source, provide a link to the Creative Commons license, and indicate if changes were made.

\section{References and Recommended Reading}

Papers of particular interest, published recently, have been highlighted as:

- Of importance

$\bullet \quad$ Of major importance

1. Fusar-Poli P, Kempton MJ, Rosenheck RA. Efficacy and safety of second-generation long-acting injections in schizophrenia: a meta-analysis of randomized-controlled trials. Int Clin Psychopharmacol. 2013;28(2):57-66.

2. Meyer EC, Carrion RE, Cornblatt BA, Addington J, Cadenhead KS, Cannon TD, et al. The relationship of neurocognition and negative symptoms to social and role functioning over time in individuals at clinical high risk in the first phase of the north american prodrome longitudinal study. Schizophr Bull. 2014;40(6):1452-61.

3. Carpenter Jr WT, Heinrichs DW, Wagman AM. Deficit and nondeficit forms of schizophrenia: the concept. Am J Psychiatry. 1988;145(5):578-83. 
4. Kirkpatrick B, Fenton WS, Carpenter Jr WT, Marder SR. The NIMH-MATRICS consensus statement on negative symptoms. Schizophr Bull. 2006;32(2):214-9.

5. Foussias G, Agid O, Fervaha G, Remington G. Negative symptoms of schizophrenia: clinical features, relevance to real world functioning and specificity versus other cns disorders. Eur Neuropsychopharmacol. 2014;24(5):693-709.

6. Foussias G, Siddiqui I, Fervaha G, Agid O, Remington G. Dissecting negative symptoms in schizophrenia: opportunities for translation into new treatments. J Psychopharmacol. 2015;29(2):116-26.

7. Austin SF, Mors O, Secher RG, Hjorthoj CR, Albert N, Bertelsen $\mathrm{M}$, et al. Predictors of recovery in first episode psychosis: the opus cohort at 10 year follow-up. Schizophr Res. 2013;150(1):163-8.

8. Bora E, Lin A, Wood SJ, Yung AR, McGorry PD, Pantelis C. Cognitive deficits in youth with familial and clinical high risk to psychosis: a systematic review and metaanalysis. Acta Psychiatr Scand. 2014;130(1):1-15.

9. Piskulic D, Addington J, Cadenhead KS, Cannon TD, Cornblatt BA, Heinssen R, et al. Negative symptoms in individuals at clinical high risk of psychosis. Psychiatry Res. 2012;196(2-3):220-4.

10. Kirkpatrick B, Buchanan RW, Ross DE, Carpenter Jr WT. A separate disease within the syndrome of schizophrenia. Arch Gen Psychiatry. 2001;58(2):165-71.

11. Jackson JH. Selected writings. New York: Basic Books; 1958.

12. Crow TJ. Molecular pathology of schizophrenia: more than one disease process? Br Med J.

1980;280(6207):66-8.

13. Chue P, Lalonde JK. Addressing the unmet needs of patients with persistent negative symptoms of schizophrenia: emerging pharmacological treatment options. Neuropsychiatr Dis Treat. 2014;10:777-89.

14. Davis MC, Horan WP, Marder SR. Psychopharmacology of the negative symptoms: current status and prospects for progress. Eur Neuropsychopharmacol. 2014;24(5):788-99.

15.• Fusar-Poli P, Papanastasiou E, Stahl D, Rocchetti M, Carpenter W, Shergill S, et al. Treatments of negative symptoms in schizophrenia: meta-analysis of 168 randomized placebo-controlled trials. Schizophr Bull. 2015;41(4):892-9.

This represents the largest meta-analysis of negative symptom treatment to date. Included are different pharmacotherapeutic agents, brain stimulation, and psychological interventions.

16. Millan MJ, Fone K, Steckler T, Horan WP. Negative symptoms of schizophrenia: clinical characteristics, pathophysiological substrates, experimental models and prospects for improved treatment. Eur Neuropsychopharmacol. 2014;24(5):645-92.

17. Moller HJ, Czobor P. Pharmacological treatment of negative symptoms in schizophrenia. Eur Arch Psychiatry Clin Neurosci. 2015;265(7):567-78.
18. Tsapakis EM, Dimopoulou T, Tarazi FI. Clinical management of negative symptoms of schizophrenia: an update. Pharmacol Ther. 2015;153:135-47.

19. Lieberman JA, Davis RE, Correll CU, Goff DC, Kane JM, Tamminga CA, Mates S, Vanover KE. ITI-007 for the treatment of schizophrenia: A 4week randomized, double-blind, controlled trial. Biol Psychiatry. 2015 Aug 31

20. Remington G. Understanding antipsychotic "atypicality": a clinical and pharmacological moving target. J Psychiatry Neurosci. 2003;28(4):275-84.

21. Harvey RC, James AC, Shields GE. A systematic review and network meta-analysis to assess the relative efficacy of antipsychotics for the treatment of positive and negative symptoms in early-onset schizophrenia. CNS Drugs. 2016;30(1):27-39.

22. Moosavi SM, Ahmadi M, Mojtahedi D, Yazdani J, M $\mathrm{BM}$. Comparison of quetiapine and risperidone in treatment of acute psychosis: a double-blind, randomized-controlled study. Global J Health Sci. 2015;7(5):41952.

23. Shoja Shafti S, Fallah JP. A comparative study between olanzapine and risperidone regarding drug-induced electrocardiographic changes. Cardiovasc Psychiatry Neurol. 2014;2014:637016.

24. Rummel C, Kissling W, Leucht S. Antidepressants for the negative symptoms of schizophrenia. Cochrane Database Syst Rev. 2006;3, CD005581.

25. Sepehry AA, Potvin S, Elie R, Stip E. Selective serotonin reuptake inhibitor (ssri) add-on therapy for the negative symptoms of schizophrenia: a meta-analysis. J Clin Psychiatry. 2007;68(4):604-10.

26. Singh SP, Singh V, Kar N, Chan K. Efficacy of antidepressants in treating the negative symptoms of chronic schizophrenia: meta-analysis. Br J Psychiatry. 2010;197(3):174-9.

27. Barnes TR, Paton C. Do antidepressants improve negative symptoms in schizophrenia? BMJ. 2011;342:d3371.

28. Yassini M, Shariat N, Nadi M, Amini F, Vafaee M. The effects of bupropion on negative symptoms in schizophrenia. Iran J Pharm Res. 2014;13(4):1227-33.

29. Shoja Shafti S, Jafarabad MS, Azizi R. Amelioration of deficit syndrome of schizophrenia by norepinephrine reuptake inhibitor. Ther Adv Psychopharmacol. 2015;5(5):263-70.

30. Vidal C, Reese C, Fischer BA, Chiapelli J, Himelhoch S. Meta-analysis of efficacy of mirtazapine as an adjunctive treatment of negative symptoms in schizophrenia. Clin Schizophr Relat Psychoses. 2015;9(2):88-95.

31. Lieberman JA, Kane JM, Alvir J. Provocative tests with psychostimulant drugs in schizophrenia. Psychopharmacology (Berl). 1987;91(4):415-33.

32. Tossell JW, Greenstein DK, Davidson AL, Job SB, Gochman P, Lenane M, et al. Stimulant drug treatment in childhood-onset schizophrenia with comorbid ADHD: an open-label case series. J Child Adolesc Psychopharmacol. 2004;14(3):448-54. 
33. Lindenmayer JP, Nasrallah H, Pucci M, James S, Citrome L. A systematic review of psychostimulant treatment of negative symptoms of schizophrenia: challenges and therapeutic opportunities. Schizophr Res. 2013;147(2-3):241-52.

34. Andrade C, Kisely S, Monteiro I, Rao S. Antipsychotic augmentation with modafinil or armodafinil for negative symptoms of schizophrenia: systematic review and meta-analysis of randomized controlled trials. J Psychiatr Res. 2015;60:14-21.

35. Shoja Shafti S, Akbari S. Intractability of deficit syndrome of schizophrenia against adjunctive modafinil. J Clin Psychopharmacol. 2016;36(1):45-9.

36. Lasser RA, Dirks B, Nasrallah H, Kirsch C, Gao J, Pucci $\mathrm{ML}$, et al. Adjunctive lisdexamfetamine dimesylate therapy in adult outpatients with predominant negative symptoms of schizophrenia: open-label and randomized-withdrawal phases.

Neuropsychopharmacology. 2013;38(11):2140-9.

37. Citrome L. Unmet needs in the treatment of schizophrenia: new targets to help different symptom domains. J Clin Psychiatry. 2014;75 Suppl 1:21-6.

38. Tiihonen J, Wahlbeck K, Kiviniemi V. The efficacy of lamotrigine in clozapine-resistant schizophrenia: a systematic review and meta-analysis. Schizophr Res. 2009;109(1-3):10-4.

39. Goff DC. Drug development in schizophrenia: are glutamatergic targets still worth aiming at? Curr Opin Psychiatry. 2015;28(3):207-15.

A useful summary of the work done to date in this area, as well as discussion of future directions.

40. Singh SP, Singh V. Meta-analysis of the efficacy of adjunctive nmda receptor modulators in chronic schizophrenia. CNS Drugs.

2011;25(10):859-85

41. Tsai GE, Lin PY. Strategies to enhance n-methyl-daspartate receptor-mediated neurotransmission in schizophrenia, a critical review and meta-analysis. Curr Pharm Des. 2010;16(5):522-37.

42. Kantrowitz JT, Woods SW, Petkova E, Cornblatt B, Corcoran CM, Chen H, et al. D-serine for the treatment of negative symptoms in individuals at clinical high risk of schizophrenia: a pilot, double-blind, placebocontrolled, randomised parallel group mechanistic proof-of-concept trial. Lancet Psychiatry.

2015;2(5):403-12.

43. Umbricht D, Alberati D, Martin-Facklam M, Borroni E, Youssef EA, Ostland M, et al. Effect of bitopertin, a glycine reuptake inhibitor, on negative symptoms of schizophrenia: a randomized, double-blind, proof-of-concept study. JAMA Psychiatry. 2014;71(6):637-46.

44. Stauffer VL, Millen BA, Andersen S, Kinon BJ, Lagrandeur L, Lindenmayer JP, et al. Pomaglumetad methionil: no significant difference as an adjunctive treatment for patients with prominent negative symptoms of schizophrenia compared to placebo. Schizophr Res. 2013;150(23):434-41.
45. Kishi T, Iwata N. NMDA receptor antagonists interventions in schizophrenia: meta-analysis of randomized, placebo-controlled trials. J Psychiatr Res. 2013;47(9):1143-9.

46. Singer P, Dubroqua S, Yee BK. Inhibition of glycine transporter 1: the yellow brick road to new schizophrenia therapy? Curr Pharm Des. 2015;21(26):3771-87.

47. Rezaei F, Mohammad-Karimi M, Seddighi S, Modabbernia A, Ashrafi M, Salehi B, et al. Memantine add-on to risperidone for treatment of negative symptoms in patients with stable schizophrenia: randomized, double-blind, placebo-controlled study. J Clin Psychopharmacol. 2013;33(3):336-42.

48. LaCrosse AL, Burrows BT, Angulo RM, Conrad PR, Himes SM, Mathews N, et al. mGluR5 positive allosteric modulation and its effects on MK-801 induced set-shifting impairments in a rat operant delayed matching/non-matching-to-sample task. Psychopharmacol (Berl). 2015;232(1):251-8.

49. Ohgi Y, Futamura T, Hashimoto K. Glutamate signaling in synaptogenesis and NMDA receptors as potential therapeutic targets for psychiatric disorders. Curr Mol Med. 2015;15(3):206-21.

50. Ellaithy A, Younkin J, Gonzalez-Maeso J, Logothetis DE. Positive allosteric modulators of metabotropic glutamate 2 receptors in schizophrenia treatment. Trends Neurosci. 2015;38(8):506-16.

51. Li ML, Hu XQ, Li F, Gao WJ. Perspectives on the mGluR2/3 agonists as a therapeutic target for schizophrenia: still promising or a dead end? Prog Neuropsychopharmacol Biol Psychiatry. 2015;60:66-76.

52. Matosin N, Fernandez-Enright F, Lum JS, Newell KA. Shifting towards a model of mGluR5 dysregulation in schizophrenia: consequences for future schizophrenia treatment. Neuropharmacology. 2015 Sep 6.

53. Wieronska JM, Zorn SH, Doller D, Pilc A. Metabotropic glutamate receptors as targets for new antipsychotic drugs: historical perspective and critical comparative assessment. Pharmacol Ther. 2016;157:10-27.

54. Zink M, Correll CU. Glutamatergic agents for schizophrenia: current evidence and perspectives. Expert Rev Clin Pharmacol. 2015;8(3):335-52.

55. Ribeiz SR, Bassitt DP, Arrais JA, Avila R, Steffens DC, Bottino CM. Cholinesterase inhibitors as adjunctive therapy in patients with schizophrenia and schizoaffective disorder: a review and meta-analysis of the literature. CNS Drugs. 2010;24(4):303-17.

56. Choi KH, Wykes T, Kurtz MM. Adjunctive pharmacotherapy for cognitive deficits in schizophrenia: metaanalytical investigation of efficacy. Br J Psychiatry. 2013;203(3):172-8.

57. Singh J, Kour K, Jayaram MB. Acetylcholinesterase inhibitors for schizophrenia. Cochrane Database Syst Rev. 2012;1, CD007967.

58. Schilstrom B, Ivanov VB, Wiker C, Svensson TH. Galantamine enhances dopaminergic 
neurotransmission in vivo via allosteric potentiation of nicotinic acetylcholine receptors. Neuropsychopharmacology. 2007;32(1):43-53.

59. Beinat C, Banister SD, Herrera M, Law V, Kassiou M. The therapeutic potential of $\alpha 7$ nicotinic acetylcholine receptor ( $\alpha 7 \mathrm{nAChR})$ agonists for the treatment of the cognitive deficits associated with schizophrenia. CNS Drugs. 2015;29(7):529-42.

60. Pohanka M. Alpha7 nicotinic acetylcholine receptor is a target in pharmacology and toxicology. Int J Mol Sci. 2012;13(2):2219-38.

61. Uteshev VV. The therapeutic promise of positive allosteric modulation of nicotinic receptors. Eur J Pharmacol. 2014;727:181-5.

62. Wallace TL, Bertrand D. Neuronal $\alpha 7$ nicotinic receptors as a target for the treatment of schizophrenia. Int Rev Neurobiol. 2015;124:79-111.

63. Deutsch SI, Schwartz BL, Schooler NR, Brown CH, Rosse RB, Rosse SM. Targeting alpha-7 nicotinic neurotransmission in schizophrenia: a novel agonist strategy. Schizophr Res. 2013;148(1-3):138-44.

64. Walling D, Marder SR, Kane J, Fleischhacker WW, Keefe RS, Hosford DA, et al. Phase 2 trial of an alpha-7 nicotinic receptor agonist (TC-5619) in negative and cognitive symptoms of schizophrenia. Schizophr Bull. 2016;42(2):335-43.

65. Huang M, Felix AR, Flood DG, Bhuvaneswaran C, Hilt $\mathrm{D}$, Koenig G, et al. The novel $\alpha 7$ nicotinic acetylcholine receptor agonist EVP-6124 enhances dopamine, acetylcholine, and glutamate efflux in rat cortex and nucleus accumbens. Psychopharmacol (Berl).

2014;231(23):4541-51.

66. Secades JJ, Frontera G. CDP-choline: pharmacological and clinical review. Methods Find Exp Clin Pharmacol. 1995; 17(Suppl B):1-54.

67. Schmidt CJ, Sorensen SM, Kehne JH, Carr AA, Palfreyman MG. The role of 5-HT2A receptors in antipsychotic activity. Life Sci. 1995;56(25):2209-22.

68. Akhondzadeh S, Malek-Hosseini M, Ghoreishi A, Raznahan M, Rezazadeh SA. Effect of ritanserin, a 5HT2A/2C antagonist, on negative symptoms of schizophrenia: a double-blind randomized placebocontrolled study. Prog Neuropsychopharmacol Biol Psychiatry. 2008;32(8):1879-83.

69. Duinkerke SJ, Botter PA, Jansen AA, van Dongen PA, van Haaften AJ, Boom AJ, et al. Ritanserin, a selective 5HT2/1C antagonist, and negative symptoms in schizophrenia. A placebo-controlled double-blind trial. Br J Psychiatry. 1993;163:451-5.

70. Khodaie-Ardakani MR, Seddighi S, Modabbernia A, Rezaei F, Salehi B, Ashrafi M, et al. Granisetron as an add-on to risperidone for treatment of negative symptoms in patients with stable schizophrenia: randomized double-blind placebocontrolled study. J Psychiatr Res. 2013;47(4):4728.

71. Noroozian M, Ghasemi S, Hosseini SM, Modabbernia A, Khodaie-Ardakani MR, Mirshafiee O, et al. A placebo-controlled study of tropisetron added to risperidone for the treatment of negative symptoms in chronic and stable schizophrenia. Psychopharmacol (Berl). 2013;228(4):595-602.

72. Kishi T, Mukai T, Matsuda Y, Iwata N. Selective serotonin 3 receptor antagonist treatment for schizophrenia: meta-analysis and systematic review. Neuromol Med. 2014;16(1):61-9.

73. Remington G, Seeman MV. Schizophrenia and the influence of male gender. Clin Pharmacol Ther. 2015;98(6):578-81.

74. Akhondzadeh S, Rezaei F, Larijani B, Nejatisafa AA, Kashani L, Abbasi SH. Correlation between testosterone, gonadotropins and prolactin and severity of negative symptoms in male patients with chronic schizophrenia. Schizophr Res. 2006;84(2-3):405-10.

75. Goyal RO, Sagar R, Ammini AC, Khurana ML, Alias AG. Negative correlation between negative symptoms of schizophrenia and testosterone levels. Ann N Y Acad Sci. 2004;1032:291-4.

76. Kaneda Y, Ohmori T. Relation between estradiol and negative symptoms in men with schizophrenia. J Neuropsychiatry Clin Neurosci. 2005;17(2):239-42.

77. Ko YH, Jung SW, Joe SH, Lee CH, Jung HG, Jung IK, et al. Association between serum testosterone levels and the severity of negative symptoms in male patients with chronic schizophrenia.

Psychoneuroendocrinology. 2007;32(4):385-91.

78. Shirayama Y, Hashimoto K, Suzuki Y, Higuchi T. Correlation of plasma neurosteroid levels to the severity of negative symptoms in male patients with schizophrenia. Schizophr Res. 2002;58(1):69-74.

79. Strous RD. Dehydroepiandrosterone (DHEA) augmentation in the management of schizophrenia symptomatology. Essent Psychopharmacol. 2005;6(3):141-7.

80. Marx CE, Keefe RS, Buchanan RW, Hamer RM, Kilts JD, Bradford DW, et al. Proof-of-concept trial with the neurosteroid pregnenolone targeting cognitive and negative symptoms in schizophrenia. Neuropsychopharmacology. 2009;34(8):1885-903.

81. Ritsner MS, Bawakny H, Kreinin A. Pregnenolone treatment reduces severity of negative symptoms in recent-onset schizophrenia: an 8-week, double-blind, randomized add-on two-center trial. Psychiatry Clin Neurosci. 2014;68(6):432-40.

82. Kardashev A, Ratner Y, Ritsner MS. Add-on pregnenolone with l-theanine to antipsychotic therapy relieves negative and anxiety symptoms of schizophrenia: an 8-week, randomized, doubleblind, placebo-controlled trial. Clin Schizophr Relat Psychoses. 2015 Jul 28

83. Usall J, Huerta-Ramos E, Labad J, Cobo J, Nunez $\mathrm{C}$, Creus $\mathrm{M}$, et al. Raloxifene as an adjunctive treatment for postmenopausal women with schizophrenia: a 24-week double-blind, randomized, parallel, placebo-controlled trial. Schizophr Bull. 2016;42(2):309-17. 
84. Feifel D, Shilling PD, MacDonald K. A review of oxytocin's effects on the positive, negative, and cognitive domains of schizophrenia. Biol Psychiatry. 2016;79(3):222-33.

85. Rich ME, Caldwell HK. A role for oxytocin in the etiology and treatment of schizophrenia. Front Endocrinol (Lausanne). 2015;6:90.

86. Oya K, Matsuda Y, Matsunaga S, Kishi T, Iwata N. Efficacy and safety of oxytocin augmentation therapy for schizophrenia: an updated systematic review and meta-analysis of randomized, placebo-controlled trials. Eur Arch Psychiatry Clin Neurosci. 2015 Aug 25

87. Kraepelin E: Dementia praecox and paraphrenia. Krieger Melbourne, Fla: Publishing Co; 1971 [originally published in 1919]

88. Muller N, Weidinger E, Leitner B, Schwarz MJ. The role of inflammation in schizophrenia. Front Neurosci. 2015;9:372.

89. Plane JM, Shen Y, Pleasure DE, Deng W. Prospects for minocycline neuroprotection. Arch Neurol. 2010;67(12):1442-8.

90. Oya K, Kishi T, Iwata N. Efficacy and tolerability of minocycline augmentation therapy in schizophrenia: a systematic review and meta-analysis of randomized controlled trials. Hum Psychopharmacol. 2014;29(5):483-91.

91. Ghanizadeh A, Dehbozorgi S, OmraniSigaroodi M, Rezaei Z. Minocycline as add-on treatment decreases the negative symptoms of schizophrenia; a randomized placebo-controlled clinical trial. Recent Patents Inflamm Allergy Drug Discov. 2014;8(3):211-5.

92. Kelly DL, Sullivan KM, McEvoy JP, McMahon RP, Wehring HJ, Gold JM, et al. Adjunctive minocycline in clozapine-treated schizophrenia patients with persistent symptoms. J Clin Psychopharmacol. 2015;35(4):374-81.

93. Khodaie-Ardakani MR, Mirshafiee O, Farokhnia M, Tajdini M, Hosseini SM, Modabbernia A, et al. Minocycline add-on to risperidone for treatment of negative symptoms in patients with stable schizophrenia: randomized double-blind placebocontrolled study. Psychiatry Res.

2014;215(3):540-6.

94. Liu F, Guo X, Wu R, Ou J, Zheng Y, Zhang B, et al. Minocycline supplementation for treatment of negative symptoms in early-phase schizophrenia: a double blind, randomized, controlled trial. Schizophr Res. 2014;153(1-3):169-76.

95. Fekadu A, Mesfin M, Medhin G, Alem A, Teferra S, Gebre-Eyesus T, et al. Adjuvant therapy with minocycline for schizophrenia (the MINOS trial): study protocol for a double-blind randomized placebo-controlled trial. Trials. 2013;14:406.

96. Lisiecka DM, Suckling J, Barnes TR, Chaudhry IB, Dazzan P, Husain N, et al. The benefit of minocycline on negative symptoms in early-phase psychosis in addition to standard care - extent and mechanism (BENEMIN): study protocol for a randomised controlled trial. Trials. 2015;16:71.
97. Qurashi I, Collins J, Chaudhry I, Husain N. Promising use of minocycline augmentation with clozapine in treatment-resistant schizophrenia. J Psychopharmacol. 2014;28(7):707-8.

98. Fagan SC, Waller JL, Nichols FT, Edwards DJ, Pettigrew LC, Clark WM, et al. Minocycline to improve neurologic outcome in stroke (minos): a dose-finding study. Stroke. 2010;41(10):2283-7.

99. Andrade C. Anti-inflammatory strategies in the treatment of schizophrenia. Expert Rev Clin Pharmacol. 2015;9(2):161-3.

100. Lee SY, Chen SL, Chang YH, Chen PS, Huang SY, Tzeng NS, et al. ALDH2 polymorphism, associated with attenuating negative symptoms in patients with schizophrenia treated with add-on dextromethorphan. J Psychiatr Res. 2015;69:50-6.

101. Chaudhry IB, Husain N, ur Rahman R, Husain MO, Hamirani MM, Kazmi A, et al. A randomised doubleblind placebo-controlled 12- week feasibility trial of methotrexate added to treatment as usual in early schizophrenia: study protocol for a randomised controlled trial. Trials. 2015;16:9.

102. Vetlugina TP, Lobacheva OA, Sergeeva SA, Nikitina VB, Nevidimova TI, Semke AV. Adjunctive use of interferon $\gamma$ inducer for treatment of patients with schizophrenia. Acta Neuropsychiatrica. 2015;16:1-8.

103. Vincenzi B, Stock S, Borba CP, Cleary SM, Oppenheim CE, Petruzzi LJ, et al. A randomized placebocontrolled pilot study of pravastatin as an adjunctive therapy in schizophrenia patients: effect on inflammation, psychopathology, cognition and lipid metabolism. Schizophr Res. 2014;159(2-3):395-403.

104. Iranpour N, Zandifar A, Farokhnia M, Goguol A, Yekehtaz H, Khodaie-Ardakani MR, Salehi B, Esalatmanesh S, Zeionoddini A, Mohammadinejad P, Zeinoddini A et al. The effects of pioglitazone adjuvant therapy on negative symptoms of patients with chronic schizophrenia: a double-blind and placebocontrolled trial. Hum Psychopharmacol. 2016 feb 8 [Epub ahead of print].

105. Sayyah M, Boostani H, Ashrafpoori M, Pakseresht S. Effects of atorvastatin on negative sign in chronic schizophrenia: a double blind clinical trial. Iran J Pharm Res. 2015;14(4):1269-74.

106. Dlabac-de Lange JJ, Knegtering R, Aleman A. Repetitive transcranial magnetic stimulation for negative symptoms of schizophrenia: review and meta-analysis. J Clin Psychiatry. 2010;71(4):411-8.

107. Freitas C, Fregni F, Pascual-Leone A. Metaanalysis of the effects of repetitive transcranial magnetic stimulation (rTMS) on negative and positive symptoms in schizophrenia. Schizophr Res. 2009;108(1-3):11-24.

108. Prikryl R, Kucerova HP. Can repetitive transcranial magnetic stimulation be considered effective treatment option for negative symptoms of schizophrenia? J ECT. 2013;29(1):67-74.

109. Shi C, Yu X, Cheung EF, Shum DH, Chan RC. Revisiting the therapeutic effect of rtms on negative 
symptoms in schizophrenia: a meta-analysis. Psychiatry Res. 2014;215(3):505-13.

110. Prikryl R. Repetitive transcranial magnetic stimulation and treatment of negative symptoms of schizophrenia. Neuro Endocrinol Lett. 2011;32(2):121-6.

111. Quan WX, Zhu XL, Qiao H, Zhang WF, Tan SP, Zhou $\mathrm{DF}$, et al. The effects of high-frequency repetitive transcranial magnetic stimulation (rTMS) on negative symptoms of schizophrenia and the follow-up study. Neurosci Lett. 2015;584:197-201.

112.• Wobrock T, Guse B, Cordes J, Wolwer W, Winterer G, Gaebel W, et al. Left prefrontal high-frequency repetitive transcranial magnetic stimulation for the treatment of schizophrenia with predominant negative symptoms: a sham-controlled, randomized multicenter trial. Biol Psychiatry. 2015;77(11):979-88.

This represents the largest trial to date involving rTMS in the treatment of negative symptoms.

113. Bersani FS, Minichino A, Enticott PG, Mazzarini L, Khan N, Antonacci G, et al. Deep transcranial magnetic stimulation as a treatment for psychiatric disorders: a comprehensive review. Eur Psychiatry. 2013;28(1):30-9.

114. Agarwal SM, Shivakumar V, Bose A, Subramaniam A, Nawani H, Chhabra H, et al. Transcranial direct current stimulation in schizophrenia. Clin Psychopharmacol Neurosci. 2013;11(3):118-25.

115. Gomes JS, Shiozawa P, Dias AM, Valverde Ducos D, Akiba $\mathrm{H}$, Trevizol AP, et al. Left dorsolateral prefrontal cortex anodal tdcs effects on negative symptoms in schizophrenia. Brain Stimul. 2015;8(5):989-91.

116. Porcelli S, Balzarro B, Serretti A. Clozapine resistance: augmentation strategies. Eur

Neuropsychopharmacol. 2012;22(3):165-82.

117. Park S, Lee MK. Successful electroconvulsive therapy and improvement of negative symptoms in refractory schizophrenia with clozapine-induced seizures: a case report. Psychiatr Danub. 2014;26(4):360-2.

118. Pawelczyk T, Kolodziej-Kowalska E, Pawelczyk A, Rabe-Jablonska J. Augmentation of antipsychotics with electroconvulsive therapy in treatment-resistant schizophrenia patients with dominant negative symptoms: a pilot study of effectiveness. Neuropsychobiology. 2014;70(3):158-64.

119. Pawelczyk T, Kolodziej-Kowalska E, Pawelczyk A, Rabe-Jablonska J. Effectiveness and clinical predictors of response to combined ECT and antipsychotic therapy in patients with treatment-resistant schizophrenia and dominant negative symptoms. Psychiatry Res. 2014;220(1-2):175-80.

120. Hasan A, Wolff-Menzler C, Pfeiffer S, Falkai P, Weidinger E, Jobst A, et al. Transcutaneous noninvasive vagus nerve stimulation (tVNS) in the treatment of schizophrenia: a bicentric randomized controlled pilot study. Eur Arch Psychiatry Clin Neurosci. 2015;265(7):589600.

121. Mikell CB, Sinha S, Sheth SA. Neurosurgery for schizophrenia: an update on pathophysiology and a novel therapeutic target. J Neurosurg. 2015;30:1-12.

122. Schooler NR, Buchanan RW, Laughren T, Leucht $S$, Nasrallah HA, Potkin SG, et al. Defining therapeutic benefit for people with schizophrenia: focus on negative symptoms. Schizophr Res. 2015;162(1-3):169-74.

123. Marder SR, Kirkpatrick B. Defining and measuring negative symptoms of schizophrenia in clinical trials. Eur Neuropsychopharmacol. 2014;24(5):737-43.

A useful discussion of methodological issues to be considered in designing and evaluating clinical trials focused on negative symptoms.

124. Levine SZ, Leucht S. Treatment response heterogeneity in the predominant negative symptoms of schizophrenia: analysis of amisulpride vs placebo in three clinical trials. Schizophr Res. 2014;156(1):107-14.

125. Compton MT, Bakeman R, Alolayan Y, Balducci PM, Bernardini F, Broussard B, et al. Personality domains, duration of untreated psychosis, functioning, and symptom severity in first-episode psychosis. Schizophr Res. 2015;168(1-2):113-9.

126. Luther L, Fukui S, Firmin RL, McGuire AB, White DA, Minor KS, et al. Expectancies of success as a predictor of negative symptoms reduction over 18 months in individuals with schizophrenia. Psychiatry Res. 2015;229(1-2):505-10.

127. Dunlop J, Brandon NJ. Schizophrenia drug discovery and development in an evolving era: are new drug targets fulfilling expectations? J Psychopharmacol. 2015;29(2):230-8. 